\title{
GÊNEROS TEXTUAIS DIGITAIS E AS ATIVIDADES DE LINGUAGENS EM SALA DE AULA
}

\author{
Evando Luiz e Silva Soares da Rocha ${ }^{1}$
}

RESUMO: Concepções de texto e ensino de linguagem à luz dos estudos em Linguística evocam discussões e contribuições para a prática docente. Neste artigo, objetiva-se discutir contribuições das definições de textos e gêneros para as atividades de linguagem. Orienta-se pela seguinte questão norteadora: de que maneira se pode abordar aspectos de linguagem contemplando gêneros digitais? Defende-se a hipótese de que os gêneros digitais refletem diferentes linguagens e dinamizam o ensino. Desenvolveu-se uma pesquisa bibliográfica revisitando os postulados de Beaugrande (2002), Marcuschi (2008; 2010), Koch (2013) e Prieto (2016). Realizou-se uma investigação de natureza qualitativa analisando um corpus composto por exemplares de gêneros digitais. Destaca-se a abordagem curricular dos PCN, Brasil (1998) e da BNCC, Brasil (2018). Dessa forma, a pesquisa evidenciou que a imersão dos gêneros digitais no ensino fornece dinamismo e recursividade para desenvolver as competências e habilidades preconizadas pela BNCC.

PALAVRAS-CHAVE: Gêneros digitais. Texto. Ensino.

\section{INTRODUÇÃO}

Neste trabalho, considerando os gêneros digitais, colocamos em discussão visões teóricas sobre textos como entidades de interação, dinâmicas e multissemióticas. Entendemos que as concepções de texto e gêneros se refletem nas práticas de ensino, por isso, pautamo-nos na abordagem de textos exemplares de gêneros digitais nas aulas de linguagem nos anos finais do Ensino Fundamental.

Embora o tema seja constantemente retomado em estudos e pesquisas no campo da linguagem, existem lacunas que denotam a necessidade de aprofundamento e reflexões sobre a relação texto, gênero e ensino. Neste caso, destacamos a relevância desse trabalho em enfatizar o papel das concepções e definições de textos e gêneros digitais nas atividades de linguagem que caracterizam as práticas de ensino.

Assumimos neste trabalho a noção de texto que o situa como entidade interacional. Pois, compreendemos que ele se atualiza no momento da interação e conforme a intenção em que se efetiva a comunicação revela funções e papéis dos participantes da interação. Os gêneros textuais, dessa forma, são vistos para além das representações de textos orais ou escritos, pois, os vemos como mecanismos que funcionam nos mais diversos contextos da vida cotidiana criando relações por meio de manifestações de linguagens entre os sujeitos e o mundo.

A rigor, conforme os Parâmetros Curriculares Nacionais, doravante PCN, as aulas de Língua Portuguesa iniciam e terminam com o texto (BRASIL, 1998). Nesse sentido, é im-

1 Instituição: Secretaria Municipal de Educação - Palmeirais/Piaui, Orcid: https://orcid.org/0000-0002-1150-340X, E-mail: evevinho@gmail.com 
prescindível entender, como se definem, como se constituem e se cumprem os propósitos interacionais dos textos, principalmente em relação aos que emanam de gêneros digitais compartilhados em ambientes virtuais da internet.

Para cumprir os propósitos deste trabalho, desenvolvemos uma abordagem bibliográfica em que se evidenciamos as definições de texto, gênero, bem como destacamos as contribuições de documentos curriculares como os PCN, Brasil (1998) e da Base Nacional Comum Curricular -BNCC, Brasil (2018) para orientar as considerações sobre as práticas de ensino de linguagem. Também desenvolvemos uma pesquisa qualitativa procedendo à análise de 03 (três) textos exemplares de gêneros digitais a saber: Memes, Instantâneo de Whats App e post de Facebook, cujas realizações multissemióticas tornam-se objeto de ensino de linguagem.

Além desse tópico de Introdução e da Metodologia, o trabalho está organizado em dois tópicos basilares de fundamentação. No primeiro, discutimos noções e definições de textos. No segundo, pontuamos a noção de gêneros textuais que assumimos, de acordo com o contexto dos gêneros digitais e tecemos considerações e reflexões sobre o ensino de. Depois, trazemos o tópico de análises e o das considerações finais.

\section{DEFININDO TEXTO}

No contexto mais atual de discussão sobre o ensino de linguagem, ainda são recorrentes paradigmas de estudo do texto como estruturas linguísticas superiores, organizadas como tais e portadoras de sentidos. Entretanto, é importante destacar que os estudos da linguagem celebram novas abordagens e definições de texto apontando para perspectivações mais completas, tanto sob o enfoque de semioses verbais e não verbais, quanto atinentes aos aspectos cognitivos, interacionais e sociodiscursivos.

O texto visto sob este prisma recobre diferentes visões sobre o funcionamento da língua e os seus aspectos interacionais. A propósito, como a própria concepção de língua e linguagem passam por evolução, o texto também tem sido travessado por estudos que ampliam suas definições. Destacamos no contexto desta discussão os estudos da linguagem que embora foquem no tratamento linguístico, também lançam olhares ou apontam para outros modos de construir e conceber o texto.

A consolidação da Linguística Textual - LT como campo da Linguística que visa ao texto como objeto de estudo, concorreu com diferentes definições de texto, bem como com diferentes abordagens analíticas e/ou interpretativas. Cabe, pois, evidenciar a investidura sociointeracionista que aqui acompanhamos. Neste caso, concebemos o texto como unidade de interação sob a perspectiva da existência do sujeito, um ser ativo e partícipe dos processos, que age sobre o outro e o mundo.

Isto posto, entendemos que o texto não está pronto e acabado, mas que é parte de uma proposta que evolui conforme a dinâmica comunicativa. Para Beaugrande (2002) em vez de Linguística Textual, a LT deve ser considerada como "ciência de texto" e, assim, considerará o contexto preservando o linguístico, o social e o interacional. Dessa maneira, concebemos o texto não só pelo aspecto lexical da língua utilizado para acessar os sentidos ou representar o mundo através dos signos linguísticos, mas também pelas motivações socio interacionais que o permeiam. 
Ainda conforme o autor, "nas descrições e explicações dessa linguística textual, sempre deverão aparecer três fatores relevantes, isto é, um ponto de vista linguístico, um ponto de vista cognitivo e um ponto de vista social;" (BEAUGRANDE, 2002, p. 15). O que se pretende não é discriminar se o texto é ou não uma unidade linguística, mas entendê-lo como convergência de ações, posições, pontos de vista, relações interpessoais.

Em relação as práticas de ensino, principalmente sobre a linguagem escrita e oralidade, Antunes (2003) aponta para o desenvolvimento de propostas que façam conexão com o real e que se faça sentido para os indivíduos. Sobre a natureza dos constituintes textuais, é preciso conceber a participação de outras semioses no processo comunicativo, portanto, unidades significativas nos textos que compõem. Nesse plano de abordagem, consideramos o texto enquanto entidade multifacetada.

Assim, "o texto é muito mais que a simples soma das frases (e palavras) que o compõem: (KOCH, 2013, p. 11, grifo da autora)". Como vemos, não é só o engendramento linguístico que concorre para a constituição de uma unidade textual. Nessa discussão de visada interacional sociocognitiva, a autora define o texto como, "realização que envolve sujeitos, seus objetivos e conhecimentos com propósito interacional (KOCH, 2016, p. 32)". É, na verdade, uma concepção de texto que o vislumbra em sua arquitetura e funções, inclusive, de acordo com os modelos oriundos do contato e convivência com a tecnologia.

Assim, cabe perceber o texto não só pelo olhar da linguagem oral ou escrita, mas também pelo plano de outros signos tais como; a imagem, o som, o gesto. No tópico a seguir delineamos uma discussão sobre noções de gêneros textuais e, mais especificamente, direcionamos nosso olhar sobre os gêneros digitais.

\section{GÊNEROS TEXTUAIS}

Neste trabalho, consideramos que os gêneros textuais frequentemente são reinventados, recriados surgem ou desaparecem conforme sejam as condições e necessidades sociocomunicativas dos indivíduos. Por isso, assumimos que a Comunicação só se realiza por meio de determinado gênero (MARCUSCHI, 2008). Dessa maneira, pontuamos nesta seção as discussões sobre os gêneros textuais digitais e as noções sobre o lugar e o papel dos gêneros no ensino de linguagem.

\section{OS GÊNEROS TEXTUAIS DIGITAIS}

A abordagem sobre gêneros textuais é um vetor de redirecionamento dos estudos da linguagem sobre os constructos socio interacionais e da comunicação humana. No percurso dessas duas primeiras décadas do século XXI, percebem-se mudanças significativas no âmbito das práticas docentes quanto à percepção dos gêneros textuais e as questões emblemáticas sobre o ensino.

Aqui é importante destacar que os primeiros estudos e reflexões sobre gêneros os situavam no campo da Literatura, naturalmente concebidos em função das discussões filosóficas que caracterizavam o contexto histórico. Ao reportarmo-nos sobre as investigações pautadas em gêneros textuais, destacamos que desde as discussões clássicas sobre a linguagem já se incutiam noções e reflexões sobre a natureza dos textos enquanto manifestações sociais, isto é, sobre gêneros. 
Essa abordagem não é nova, o que ocorre é que no momento são empreendidos novos olhares sobre os gêneros (MARCUSCHI, 2008). Principalmente a discussão sobre a definição e as marcas que os tornam "relativamente estáveis" conforme a vertente Bakhtiniana apregoa. Por outro lado, dada a configuração da sociedade contemporânea perante às inovações e, consequentemente a inserção de mecanismos da tecnologia nos processos de interação, os ditos gêneros digitais ganham corpo e determinam novas formas de uso e compreensão da linguagem.

Diante desse quadro, discutimos o aparecimento massivo dos textos produzidos em meios eletrônicos e, os quais servem aos anseios dessa sociedade contemporânea, cabendo, pois, à escola ajustar e tratá-los como tais (MARCUSCHI, 2008). Pois, para o autor, são textos compreendidos a partir dos fatores de textualidade, do estilo composicional e dos sentidos que sugerem aos interactantes.

No que diz respeito aos gêneros digitais, é preciso considerar a presença determinante das tecnologias e fluidez dos ambientes virtuais em que eles são criados e veiculados. Além disso, são caracterizados pela inventividade, liberdade de escrita e combinações multissemióticas. Os gêneros digitais correspondem aos formatos em que a escrita é viabilizada e torna-se dinâmica e colaborativa a partir de meios eletrônicos (MARCUSCHI, 2010).

Conforme expos o autor, os gêneros digitais possuem particularidades que só são compreendidas em função dos domínios dos meios ou aparatos tecnológicos com que são produzidos. A propósito, chamamos a atenção para o papel da escola frente ao universo de mudanças e tecnologia, conforme Prieto (2016);

a Internet é uma espécie de protótipo de novas formas de comportamento comunicativo. Se bem aproveitada, ela pode tornar-se um meio eficaz de lidar com as novas práticas interacionistas da linguagem (PRIETO, 2016, p. 5).

Os gêneros digitais compartilham características relacionadas aos meios virtuais onde são produzidos e veiculados. Exemplificam os gêneros digitais os textos apresentados sob a forma de meme, instantâneo de Whats App, post de facebook, banner digital. Trata-se, pois, de textos dinâmicos, marcados por eventos multissemióticas e definidos conforme a demanda de práticas e ações sociais que se desenvolvem num contexto/suporte especifico, a internet.

A marca dos gêneros digitais é que eles reúnem num mesmo espaço vários modos de apresentação, isto é, recorrem à multimodalidade para cumprirem os seus propósitos. Nisso, embora denotem leitura rápida e o visual seja mais atraente, os textos são carregados de sentidos, revestem-se de discursos vários, alcançando

E ainda, sobre os gêneros textuais;

o fundamental não é o conceito teórico que se adota, mas a perspectiva de que os gêneros são mais bem compreendidos se encarados como se encontram no mundo real, e não abstraídos como objeto de preocupação pedagógica (BEZERRA, 2017, p. 61).

De maneira geral, os gêneros digitais demandam ações nas mais variadas esferas das atividades humanas e vida sociais. Logo, os indivíduos compartilham de diferentes ferramentas do mundo tecnológico e com elas e por meio delas interagem constantemente. 


\section{QUESTÕES DE ENSINO}

Com a proposição dos Parâmetros Curriculares Nacionais nos anos da década de 1990, o ensino de língua materna foi redefinido segundo a abordagem de gêneros textuais. Nesta linha, uma inovação na prática foi tratar a análise linguística organizada no eixo "uso - reflexão - uso (BRASIL, 1998, p. 62)", incluindo também nesse universo, os textos orais representativos do contexto social dos aprendentes.

Assim, os PCN engenharam novos paradigmas para o ensino de linguagem numa abordagem sociointeracionista fortemente marcada pelo quadro teórico metodológico do Interacionismo Sociodiscursivo - ISD. Neste caso, conforme o referido documento, os gêneros são "famílias de textos que compartilham características comuns (BRASIL, 1998, p. 22)".

O foco nas regras ou trabalhar a gramática como atividade fim em si mesma visa unicamente preparar os aprendentes para o domínio da norma culta, ao contrario disso, os PCN preconizam que o ensino de linguagem deve evidenciar as variedades da língua, de maneira que os indivíduos tornem-se dominantes dessas várias modalidades (BRASIL,1998).

As discussões sobre as aulas de linguagem põem em evidencia o tratamento que se deve dar aos aspectos interacionais da linguagem, pontuando que sejam consideradas as semioses não verbais, os elementos dos contextos socioculturais e os eventos próprios da oralidade.

A propósito, a BNCC orienta a abordagem a partir de gêneros que circulam nas diversas esferas das atividades humanas e também acompanha a perspectiva sociointeracionista (BRASIL, 2018). Assim, caracteriza o texto a partir do parâmetro de unidade multissemiotica, isto é, o texto como espaço/lugar de interação comporta diferentes modos de expressão, logo afeiçoa-se ao conjunto de experiências sociodiscursiva dos indivíduos.

O desenvolvimento das atividades de linguagem sob a ótica da BNCC, deve ser pautado em competências e habilidades considerando gêneros que se realizam em diferentes esferas das atividades humanas para culminar com práticas de análise linguística e semiótica (BRASIL, 2018).

\section{METODOLOGIA}

O presente estudo de caráter qualitativo e descritivo, cujo objeto de análise é constituído por quatro textos exemplares de gêneros digitais dispostos em sítios eletrônicos da internet, acompanha as discussões sobre o ensino de linguagem e as concepções de texto e suas manifestações. Assim, as considerações sobre a constituição multissemiotica dos textos é vista a partir da abordagem de gêneros digitais.

Para o alcance dos propósitos de análise, selecionados em endereços eletrônicos. Apesar de passar por um tratamento linguístico, o foco das análises deu-se sobre a estrutura verbo imagética dos exemplares escolhidos. Assim, manteve-se a estrutura original dos textos, conforme encontrados nas fontes virtuais.

Por meio deste procedimento, procurou-se descrever discursivamente os achados da pesquisa situando a abordagem dos gêneros digitais numa perspectiva de ensino condizente com as práticas que aliam semioses verbais, não verbais e mistas. As categorias postas em discussão discricionam os aspectos composicionais, estilos de linguagem, seleção e organização das mensagens, bem como a apresentação linguageiras dos enunciados verbais sob o ponto de vista do ensino de Gramática. 


\section{ANÁLISES}

Pensar uma prática de ensino de linguagem priorizando conhecimentos, experiências e contexto sociocultural dos sujeitos requer trazer para o centro da questão os textos que emanam das práticas cotidianas. $\mathrm{O}$ contato com a tecnologia, bem como com os gêneros digitais é inevitável. Em vista disso, cabe a escola e aos profissionais alinharem suas práticas de forma que contemplem os textos próprios do universo digital.

Inicialmente, descrevemos uma abordagem a partir do gênero Meme, cujas características o situam como vento digital próprio de interações e trocas de mensagens nos ambientes virtuais da internet. Caracteristicamente o gênero apresenta-se pela escolha de imagens que se associem a uma determinada temática (política, personalidades, entretenimento) e, sobre elas enunciam textos verbais, geralmente curtos, contrastando a cor das letras a superfície imagética.

No caso, temos um texto produzido por ocasião do envolvimento do jogador Neymar Jr. com uma modelo que o acusou de ter cometido crime de estupro. Como o fato foi bastante noticiado pela imprensa e ganhou destaque durante quase todo o mês de junho de 2019, a situação propiciou a criação de memes, cujo exemplar foi divulgado em perfis de redes sociais e repositório da internet, tal como representado no exemplar dado na fig. 1, vejamos.

\section{Neymar vai até a delegacia mostrar os prints}

\section{Os policiais lendo os prints:}

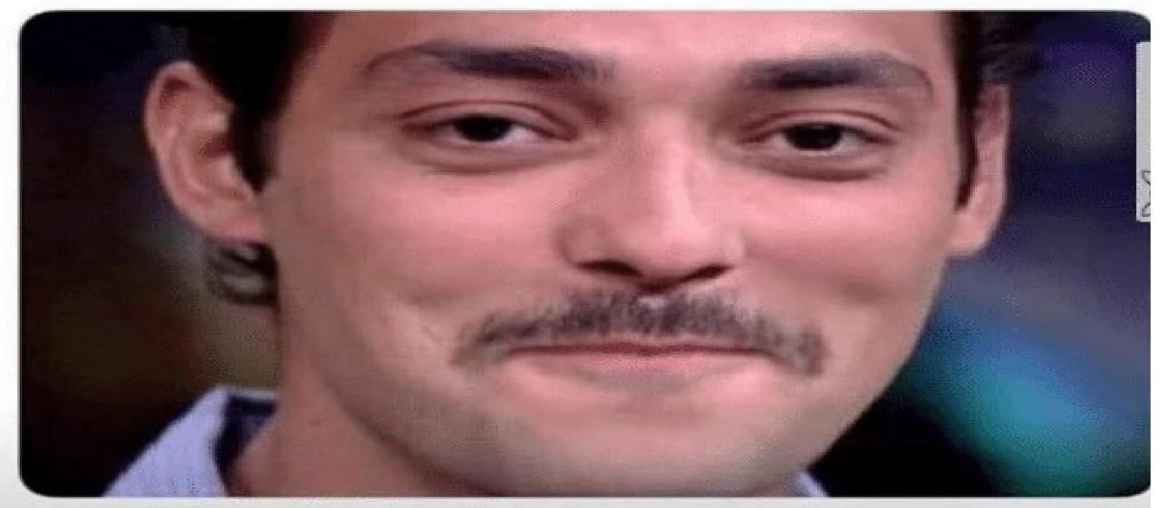

Kkkkkkkkkk

Figura 01 - Meu meme de hoje

Mesmo não constando com volumosas descrições na literatura especializada, o Meme assume um importante papel dentre as formas de interação que envolvem recursos semióticos variados, principalmente provenientes da internet. O exemplo em comento, pode despertar diferentes visões se contemplado no ensino de linguagem. Não se recomenda que seja uma abordagem unilateral apenas para a mera descrição das características e funçoes do gênero, uma vez que antes de olhar para o texto, é preciso que o sujeito aprendente tenha conhecimento sobre o contexto de produção. ${ }^{2}$

Além disso, é interessante que se perceba a atualização por que passa um texto ao ser realizado num determinado gênero, sendo assim, só há dinamicidade e mobilização dos en-

2 Fonte: Disponível em;< https://observatoriodosfamosos.uol.com.br/destaques/a-web-nao-perdoa-veja-os-memes-sobre-neymar-apos-acusacao-de-estupro>. Acesso em: 14/05/2020. 
volvidos na situação do ensino se o contexto de produção e circulação da mensagem for o contexto que vivenciam. Como o gênero alberga semioses verbais e imagéticas isso requer do leitor/interactante habilidades específicas.

Neste caso, consideramos que diferentes leituras devem ocorrer afim de se compreender que a composição de sentidos varia entre o cômico, criado de forma espontânea e a reelaboração da realidade a partir de um fato vivido socialmente. Aqui, há possibilidades de se demandar atividades que desafiem o aprendente a interagir com o texto por meio do que é tácito, explícito ou em função do contexto que tornou saliente a situação comunicada.

Aqui, pode-se entender porque a discussão posta sobre o que define o texto não pode reduzir-se ao aspecto verbal sob pena de limitar a construção de sentidos à realização da linguagem escrita. Conforme a BNCC deve-se atentar para o trabalho com esses gêneros visando dentre outras coisas a escrita colaborativa, donde os sujeitos, na interação, tanto possuem projetos de ação com os outros, quanto de ação sobre os outros (BRASIL, 2018).

No tocante ao texto, primeiro, não se deve ressaltar a primazia de uma semiose sobre outra, pois não existe sentidos prontos e imutáveis, existem pistas que conduzem o leitor no seu percurso de leitura. Segundo, a percepção da imagem não encerra o conteúdo linguístico e vice-versa, como também não há um limite que defina onde começa e onde termina cada leitura. Por último, a junção cotexto/contexto é que faz revelar os sentidos e as possíveis interpretações.

É salutar, o olhar sobre a escrita, de maneira que o aprendente reflita sobre as diferentes manifestações, inclusive percebendo como ocorre esse modelo tão recorrente no dia a dia, que é muito próximo da oralidade e, não exige domínios estanque entre o padrão e o não padrão. Neste caso, defender práticas que integrem o gênero meme promovendo o conhecimento sobre a linguagem e seus usos culmina com propostas de reflexão sobre o que se ensina e como se ensina.

A seguir, trazemos na fig.02 uma representação do gênero post de facebook. Neste caso, selecionamos o texto a partir de um perfil de rede social, cuja identidade foi extraída para assegurar o anonimato tendo em vista os fins desta análise. Neste caso, discutimos sobre um formato que carrega em sua gênese as especificidades da rede social que lhe dá suporte, o facebook. A propósito, os textos desse gênero expressam estados de espírito dos indivíduos, revelando por meio da linguagem multissemiotica, dentre outras, facetas cômicas, compenetradas, altivas dos participantes.

Percebemos que uma característica marcante no gênero é a constituição multimodal, o que permite ao leitor traçar diferentes pontos de partida para a leitura e compreensão da mensagem. Antes de qualquer investida ou proposta de análise sobre o texto, é preciso ativar conhecimentos prévios relacionados ao gênero, aos suportes digitais, às linguagens, ao estilo e ao conteúdo. 
Acharam que estavam esperando a lotação pra ir no mc donalds / mas estavam esperando a enfermeira pra tomar injeção. \#tbtdogolpe

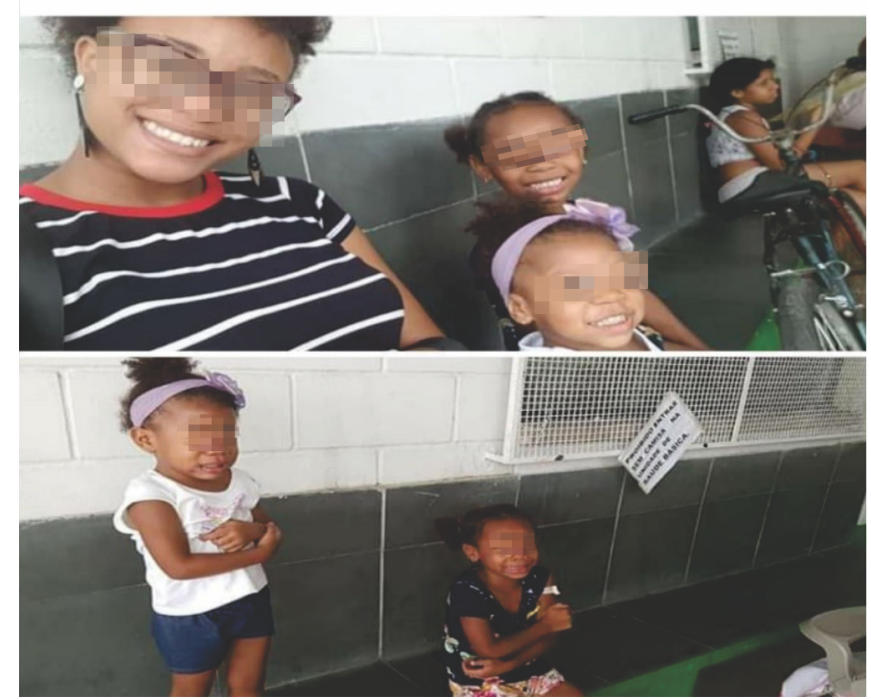

Figura 02 - \#Tbt do golpe

Fonte: Arquivo do pesquisador, 2019.

Entende-se que didatizar textos que são produzidos e veiculados em ambientes digitais, sinaliza uma conexão entre o que se ensina e mundo das experiências compartilhadas pelos sujeitos. Os gêneros digitais, quer pelo caráter emergente, quer pela natureza multissemiotica apropriam-se de meios interativos recortados das vivências cotidianas. A priori devemos trabalhar os gêneros que circulam no meio onde os indivíduos atuam (BRASIL, 1998), o caso em comento, justifica essa assertiva.

No caso do post de facebook, os propósitos interacionais ocorrem por via de semioses que se complementam, não se trata de uma sobreposição do imagético sobre o verbal e vice-versa, da mesma forma, entende-se que a superfície cotextual não expõe os sentidos, mas, dá pistas para que o leitor evolua na interpretação e compreensão global do texto. Um ponto de partida para o trabalho com as linguagens deve ser a análise linguística e semiótica (BRASIL, 2018), aqui apoiada, por exemplo, na percepção de como os interlocutores lidam com a informação linguística contida no título da figura e no interior do post, precedida pelo símbolo "\#".

Ainda em relação ao texto, a sua conjuntura multissemiotica suscita diferentes análises como:

i. Descrições sobre a escrita próxima aos eventos da oralidade;

ii. Representação de relações de concordância;

iii. Convenções da escrita e efeitos de sentidos pretendidos pelas saliências de linguagem;

iv. Relação de poder estabelecida pelos elementos do texto;

v. Eventualidades e oposições deflagradas no texto;

vi. Correlação entre o verbal e o não verbal considerando o que se diz e como se diz; vii. Comparações entre eventos ou instâncias do texto que demarcam as ações.

A função da escola em ensinar a linguagem padrão por meio da abordagem gramatical é uma posição evidenciada na BNCC, entretanto, o texto é a unidade de onde emanam as 
atividades de linguagem (BRASIL, 2018). Então, a abordagem do gênero post de facebook, dentre outras possibilidades, desperta reflexões sobre a linguagem padrão e não padrão nas ocorrências da escrita considerando-se o contexto de produção e recepção.

No último exemplo, analisamos um instantâneo de Whats App. A proposta neste caso, é conduzir o sujeito numa reflexão sobre a interação com características de trocas simultâneas de mensagens, principalmente refletindo sobre construções que dependendo do contexto requer diferentes domínios da linguagem escrita. Além disso, o recorte apresentado é bastante sugestivo para a exploração multissemiotica.

O contexto de onde extraímos o recorte evidencia passagens de um diálogo ocorrido entre setor de cobrança de uma empresa e o cliente comprador. A pesar de marcado pelo de uso de escrita rápida, econômica, desprovida de profundidade semântica e sintaxe livre, os textos veiculados no mensageiro Whats App por manifestarem usos correntes da língua, tanto podem ser realizados em formatos informais, quanto em formatos mais rigorosos acompanhando o formalismo da escrita padrão sem fugir do propósito da comunicação instantânea.

Vejamos como isso ocorre no exemplar disposto na fig. 03.

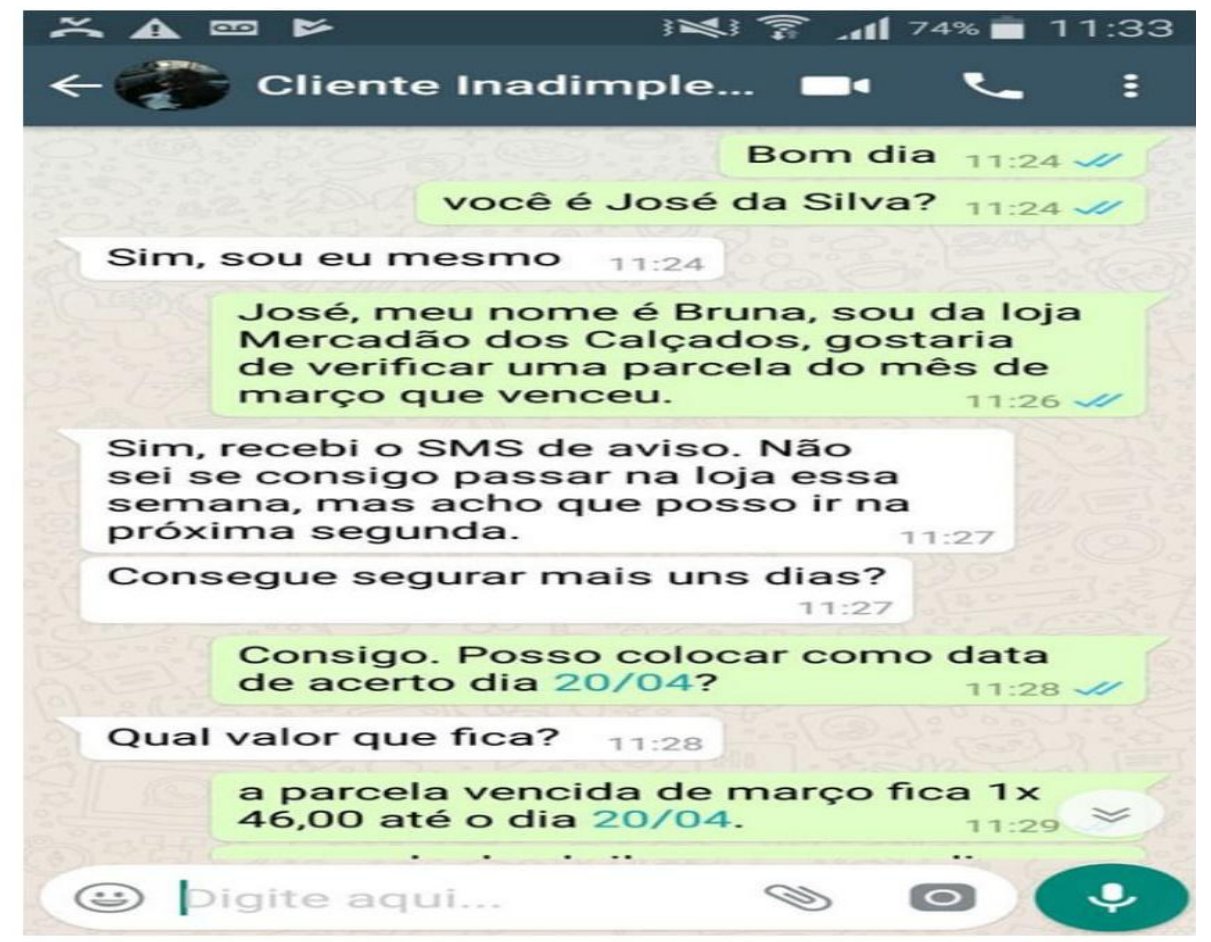

Figura 03. Instantâneo de Whats App ${ }^{3}$

A imersão dos gêneros digitais nas aulas de linguagem possibilita uma flutuação das análises linguísticas mediadas entre o simples e o complexo, o verbal e o não verbal os explícitos e os implícitos. As marcas das semioses não verbais e a iconicidade presente na cena comunicativa permite que se trabalhe os assuntos periféricos, mas inferíveis na concepção global do texto exposto no mensageiro. Uma característica dos gêneros digitais é a forma síncrona ou assíncrona da interação (MARCUSCHI, 2010).

No caso da fig.03, o instantâneo de Whats app remete a uma ocorrência de interação síncrona, os participantes estão enviando e recebendo mensagens num mesmo intervalo de tempo, o que pode ser constatado acompanhando-se o registro no próprio texto, cujas marcas

3 Fonte; Disponível em:<https://meucrediario.com.br/blog/wpcontent/uploads/2018/05/image1-1.png>. Acesso em: $05 / 06 / 2020$. 
semióticas confirmam o envio, o recebimento e a leitura. É interessante discutir o contexto de produção, quem produziu, por que produziu a mensagem, como a mensagem está explicitada.

Além disso, o gênero é favorável ao campo da multimodalidade, neste caso, o aprendente pode ser desafiado a compreender a partir de signos não verbais nuances da mensagem que às vezes escapam numa leitura desatenta ou focada apenas nas linhas e entrelinhas da mensagem escrita. Mais que conceber o texto pela saliência das linguagens, a abordagem deve mobilizar o aprendente para entender a organização e funcionamento da língua em situações de usos reais.

Em vista disso, o texto pode encaminhar situações em sejam pertinentes discussões sobre os domínios formais ou informais da linguagem, o propósito comunicativo, a apropriação da simbologia usada no contexto de produção e recepção de instantâneos de Whats App, as convenções da língua e as marcas discursivas que efetivam as intenções dos enunciadores. Entendemos que "o professor precisa saber desconstruir e reconstruir o contexto tecnológico (PRIETO, 2016)".

\section{CONSIDERAÇÕES FINAIS}

Nas discussões apresentadas neste trabalho, os recursos expressivos tradicionalmente descritos com o valor da expressão verbal determinando os sentidos é apenas parte dos constituintes textuais com os quais os indivíduos lidam em suas práticas sociais. Por isso, destacamos que a definição e o arcabouço teórico sobre texto constantemente passam por reflexões, assim, novas definições, formas de abordagem e conexão com outras áreas encaminham o ensino de linguagem para a percepção dos mecanismos interacionais que caracterizam os gêneros.

Cumprimos o objetivo desta pesquisa desvelando nuances de como se pode abordar os gêneros digitais focando no processo de ensino e, sobretudo nas características que se manifestam no próprio texto como forma de interação. A posição que assumimos sobre texto e gênero comporta diferentes olhares e reflexões sobre os modos como as atividades de linguagem podem envolver os aprendentes ao contemplar as práticas de linguagem em são partícipes. Consideramos dessa forma, que a abordagem dos gêneros textuais digitais dinamiza o ensino e torna saliente as diferentes semioses que atribuem sentido aos textos.

Além disso, entendemos que o processo de exame da linguagem por ela mesma não é produtivo, pois os textos atualizam-se constantemente e os participantes das interações são ativos. Neste sentido, ao evidenciarmos os textos que circulam em ambientes virtuais da internet, consideramos a fluidez da tecnologia e o propósito comunicativo como bases para descrever ocorrências de interações síncronas e assíncronas, textos multissemióticas e escrita definida em função do contexto.

Então, a pesquisa encetou discussões pontuais sobre o modo como as atividades de ensino podem apoiar-se em gêneros textuais digitais que albergam diferentes linguagens e são dinâmicos, corroborando a assertiva que definimos como hipótese. Em vista disso, a análise linguística e semiótica preconizada pela BNCC encontra nos nesses gêneros um vasto campo para explorar recursos comunicativos e interacionais. 


\section{DIGITAL TEXTUAL GENRES AND LANGUAGE ACTIVITIES IN THE CLASSROOM}

ABSTRACT: Conceptions of text and language teaching in the light of studies in Linguistics evoke discussions and contributions to teaching practice. This article aims to discuss contributions from the definitions of texts and genres to language activities. It is guided by the following guiding question: how can language aspects be addressed, contemplating digital genres? The hypothesis is defended that digital genres reflect different languages and make teaching more dynamic. A bibliographical research was developed revisiting the postulates of Beaugrande (2002), Marcuschi (2008; 2010), Koch (2013) and Prieto (2016). A qualitative investigation was carried out analyzing a corpus composed of copies of digital genres. The curricular approach of PCN, Brazil (1998) and BNCC, Brazil (2018) stands out. Thus, the research showed that the immersion of digital genres in teaching provides dynamism and recursion to develop the competencies and skills recommended by BNCC.

KEYWORDS. Digital genres. Text. Teaching.

\section{REFERÊNCIAS}

ANTUNES, Irandé. Aula de português: encontro e interação. São Paulo: Parábola, -2003.

BRASIL, Ministério da Educação, Secretaria de Educação Fundamental. Parâmetros Curriculares Nacionais: Língua Portuguesa. Brasília, 1998.

BRASIL. Secretaria de Educação Básica. Base Nacional Comum Curricular - BNCC. Secretaria de Educação Básica. Brasília, MEC/SEB, 2018. Disponível em: http://basenacionalcomum.mec.gov. br/wpcontent/uploads/2018/04/BNCC_19mar2018_versaofinal.pdf. Acesso em: março de 2020.

BEZERRA, Benedito Gomes. Gêneros no contexto Brasileiro: questões [meta]teóricas e conceituais. 1. ed. São Paulo: Parábola Editorial, 2017.

BEAUGRANDE, Robert de. Lingüística textual: para novas margens? Fundação de Amparo à Pesquisa de Minas Gerais - FAPEMIG. Tradutor: Hans Peter Wieser. Universidade Estadual do Ceará. Disponível em:

<http://www.periodicos.letras.ufmg.br/index.php/relin/article/viewFile/2331/2280>. Acesso: em maio de 2020.

KOCH, Ingedore Villaça. A coesão textual. 22. ed. $2^{\circ}$ reimpressão. - São Paulo: Contexto, 2013.

MARCUSCHI, Luiz Antônio. Produção textual, análise de gênero e compreensão. São Paulo: Parábola Editorial, 2008.

MARCUSCHI, Luiz Antônio. Gêneros textuais emergentes no contexto da tecnologia digital. In: MARCUSCHI, L. A. \& XAVIER A. C. Hipertexto e gêneros digitais: novas formas de construção de sentido. 3. ed. São Paulo: Cortez, 2010.

PRIETO, Sandra. A importância dos gêneros digitais nas escolas. Sistema Cibernética e Informática. Volume 13 - Número 03. 2016. 